\title{
Plain Aviation English - Qualitative and Quantitative Interpretation
}

\author{
Anatoliy Vitryak \\ Dept. of Foreign Languages, Kirovohrad Flight Academy \\ Dobrovoslky st. 1, 25005, Kirovohrad, Ukraine \\ E-mail: a.vitryak@ukr.net \\ Boris Slipak \\ Dept. of Foreign Languages, Kirovohrad Flight Academy \\ Dobrovoslky st. 1, 25005, Kirovohrad, Ukraine \\ Tel: +380-66-269-59-22Ｅ-mail: borisslepask@mail.ru \\ Kirpitnyov Serhii (Corresponding author) \\ Dept. of Foreign Languages, Kirovohrad Flight Academy \\ Dobrovoslky st. 1, 25005, Kirovohrad, Ukraine \\ E-mail: serge.ksv@gmail.com
}

Received: September 3, 2016 Accepted: September 16, 2016 Published: September 17, 2016

doi: $10.5296 /$ jsss.v4i1.9478

URL: http://dx.doi.org/10.5296/jsss.v4i1.9478

\begin{abstract}
The article deals with the still topical problem of plain aviation English. This problem has been highlighted by ICAO in its 'Manual on the Implementation of ICAO Language Proficiency Requirements' (Doc 9835). According to this 'Manual', each pilot and air traffic controller are required to have a good ranked command of not only standardized radiotelephony phraseologies which remains dominant but also of plain English intended to be used in the cases which are not covered by the phraseologies. As far as the authors are aware, the concept of plain aviation English has remained mainly declarative so far. The
\end{abstract}


article under consideration is aimed to make up qualitatively quantitatively for this lack. To master plain aviation English, along with the phraseologies, means in fact to acquire natural language competency.

Keywords: Plain aviation English, Exerciser, Psychocybernetics, Computer-based technologies

The notion 'plain English' has been made significant and pertinent to aviation lingual problems by ICAO in its 'Manual on the Implementation of ICAO Language Proficiency Requirements' (Doc 9835). That's why it seems appropriate to say about 'plain aviation English' as the synonymic expression to the 'general aviation English'. But so far the notion 'plain English' relating to flight has remained purely declarative. At the same time, it seems important, first of all for pedagogical purposes, to make the notion 'plain aviation English' linguistically explicit, in other words, to find out and present its lexical and structural (grammatical) filling.

However, as far as we are informed, the investigations and proper instructional materials specially dedicated to plain English used in radiotelephony, especially to its instruction, are not widely known. It is obvious now that it is necessary to teach future aviation specialists (pilots and air traffic controllers) not only standardized radio telephony phraseologies (which has always been regarded as natural and obligatory) but also plain aviation English. The main authentic grammatical tendencies of plain aviation English are certainly to be taken into consideration and brought into play.

'Plain aviation English' may be denoted as a sub-set of English which, in its synthetic form, provides the adequate lingual (language/speech) support of air traffic in all those cases which are not covered by the phrasal reserve of the standardized radiotelephony.

In other words, it is a variety of English intended for the full lingual satisfaction of all pre-flight, flight and post-flight requests and demands.

The Laboratory of Computer-Based English Instruction Technologies of Kirovohrad Flight Academy of the National Aviation University has developed and introduced into pedagogical process 'A Plain Aviation English Exerciser'.

'Lingual exerciser' is defined as the synthetic (structural plus lexical) consecutive (step by step) trainer of structural (grammatical) operations and their successive aggregating (combination of two and more operations each of which has been separately practiced before - to be $\rightarrow$ to have $\rightarrow\{$ to be + to have $\} \rightarrow$ the Simple Tenses $\rightarrow$ the Continuous Tenses $\rightarrow\{$ the Simple Tenses + the Continuous Tenses\}, etc.).

The lingual 'Exerciser' developed and approbated in the Academy is meant to form the representative operational grammatical (the system of the Tenses) and lexical competence within the framework of the authentic plain English textual material involved in the air-ground communications, internal cockpit talks and public addressing. The phrasal material which belongs to standardized phraseologies was excluded. 
The 'Exerciser' performs functions of formation of natural lexical and structural competency pertaining to various flight circumstances. The adequate satisfaction of all lingual flight requests and demands is ensured by the sufficient common-use and specific aviation lexical arsenal as well as by the possibility of subconscious actualization of the required structural, first of all predicative, operations.

The computer-based 'Exerciser' under consideration is intended for entirely out-of-class self-study which, in case of aviation training establishments, is to be indispensably and objectively assessed by the classroom testing based on the randomly-selected stepped phrasal material taken from the just studied unit or units. Besides educational establishments, it may be used by professional specialists to consolidate their grammatical competence and lexical provision in the period between the previous and following official testing sessions.

The sampling population which represents the lingual structure of plain aviation English is made up of about 4000 sentences taken from recordings of air traffic communications as a result of their continuous survey. They were distributed on the basis of the following grammatical operations which constitute the menu of the Exerciser: 'To be' $\rightarrow$ 'To have' $\rightarrow$ 'The Simple Tenses' $\rightarrow$ 'The Continuous Tenses' $\rightarrow$ 'The Perfect Tenses' $\rightarrow$ 'The Perfect Continuous Tenses' $\rightarrow$ 'The Passive Voice' $\rightarrow$ 'The Modal Verbs'. $\rightarrow$ Usage of the Past Simple Tense instead of the Present Perfect Tense. $\rightarrow$ Usage of the Present Simple Tense instead of the Present Continuous Tense.

The two latter syntax-oriented tendencies which are characteristic of plain aviation English are being explicated below:

1) 'Usage of the Past Simple Tense instead of the Present Perfect Tense' ("They chose the alternative airport." $\rightarrow$ They have chosen the alternative airport. / "We didn't hear your instruction." $\rightarrow$ We haven't heard your instruction. / "You entered the runway at the wrong point." $\rightarrow$ You've entered the runway at the wrong point. / "Did you hear that?" $\rightarrow$ Have you heard that? / "We came out from under fog." $\rightarrow$ "We've come out from under fog. / "We lost a door." $\rightarrow$ We have lost a door. / "We hit birds and lost thrust on both engines." $\rightarrow$ We have hit birds and lost thrust on both engines. / "I engaged the autopilot." $\rightarrow$ I have engaged the autopilot. / "Did you increase power?" $\rightarrow$ Have you increased power? / "We omitted position reports." $\rightarrow$ We have omitted position reports.)

2) 'Usage of the Simple Present Tense instead of the Present Continuous Tense'. ("We lose power on all engines." $\rightarrow$ We are losing power on all engines. / "We head for the airport." $\rightarrow$ We are heading for the airport. / "We fly in the cloud." $\rightarrow$ We are flying in the cloud. / "We keep the taxiway clear." $\rightarrow$ We're keeping the taxiway clear. / "The autopilot doesn't work." $\rightarrow$ The autopilot isn't working. / "Why don't you go direct?" $\rightarrow$ Why aren't you going direct? / "Do you watch any smoke?" $\rightarrow$ Are you watching any smoke? / "We descend very quickly." $\rightarrow$ We are descending very quickly. / "I offer you radar assistance." $\rightarrow$ I am offering you radar assistance. / "Another aircraft follows you." $\rightarrow$ Another aircraft is following you.)

Since the recordings dealt with relate to 'flight itself', it is appropriate to say in our case about 'plain aviation English - flight'. 


\section{Macrothink}

We find worth mentioning once more that there are two main modes of putting into play the 'Exerciser' - the preceding wholly self-contained work accompanied by full sound and vocabulary support, which is provided for out-of-class activities, and the following through time-limited testing which allows an instructor to use the required and timely corrective directions.

Besides the grammatical predicative verbal competence, the lexical capability is also regularly formed by means of the matching procedures and specific final semantic grouping.

The examples of the matching lexical procedure (verbs and nouns) are presented below:

1) to the runway

decrease

to (about fuel)

state

to (about the traffic volume)

enter

to intentions

disembark

to the passengers

remain

to the aircraft give

to vectors repair

2)

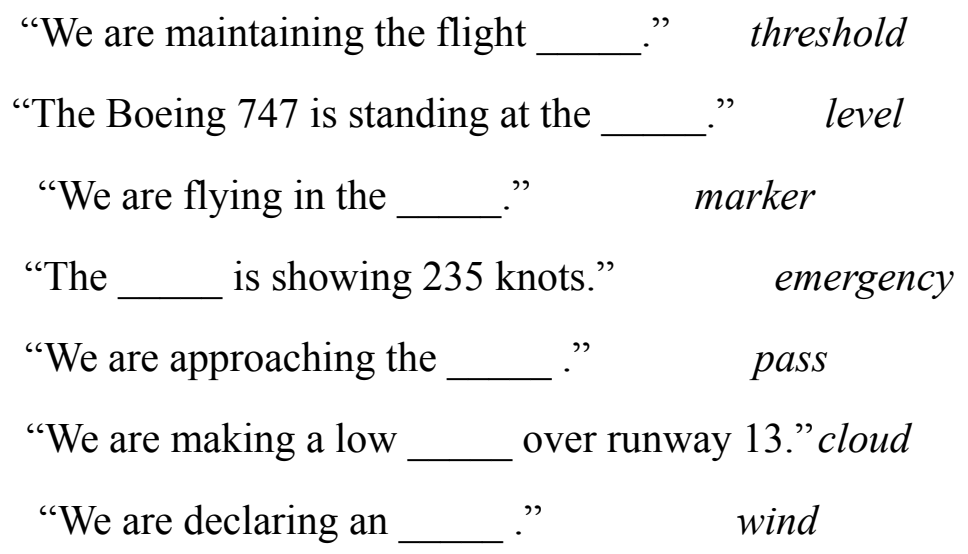

Figure 7 was chosen deliberately, not by chance. It corresponds to the magic figures of George Miller $(7 \pm 2)$ which reflect the number of objects that a human can hold in his memory on a single occasion.

It seems very valuable that the 'Exerciser' provides the flexible feedback between the user and the computing means throughout the whole learning activities any step of which is safely controllable. Three possible responses of the learners are taken into account: 1) first attempt - a) correct and on time; b) correct; not on time $\rightarrow 2$ ) second unassisted attempt - correct or incorrect; $\rightarrow 3$ ) third attempt assisted - till the correct re-entering of the answer.

We'd like to point out that the three most frequented verbal predicative operations in plain aviation English are connected with usage of to be, the Simple Tenses and the Continuous 
Tenses (mainly in the present real time), their relative frequencies being respectively 0.19 , 0.22 and 0.16 (57\% of the whole textual material).

Some examples taken from the unit "Progressive Tenses" are given below:

(cont.pr.) "We _ fall_ into a spin." $\rightarrow$ We are falling into a spin.

(cont.pr.) "I experience heavy ice buildup at this level." $\rightarrow$ I am experiencing heavy ice buildup at this level.

(cont.p.) "We_ maintain flight level two four zero" $\rightarrow$ We were maintaining flight level two four zero.

Thus, the grammatical (verbal) and lexical (nouns) competencies are being formed.

One of the specific procedures employed in the 'Exerciser' implies the insertion of a proper word when the problematic position is not explicit. This procedure requires from a student making a preliminary formal analysis of the structure of a sentence (this formal procedure being one of the obligatory and primary in machine translation).

Below two tasks are presented as examples of this very valuable, to our mind, formal procedure.

(simp.p.) Captain's wind screen crack due to bird strike. $\rightarrow$ "Captain's wind screen cracked due to bird strike". / (cont.pr.) The weather at your destination get worse $\rightarrow$ "The weather at your destination is getting worse". / (perf.pr) Air traffic control system put us into a holding pattern. $\rightarrow$ "Air traffic control system has put us into a holding pattern".

Also, it seems worthy of mentioning that the phrasal material collected for the 'Exerciser' has enabled to obtain, on the one hand, the alphabetically-ordered plain aviation English-Russian vocabulary, on the other hand, the frequency list of English words making it up. Fifty most frequented notional words with their relative frequencies are presented below:

runway (0.95\%), flight (0.56\%), engine (0.54\%), down (0.46\%) (touch down, shut down, let down, come down, gear down, etc.), right (0.45\%), landing $(0.44 \%)$, gear $(0.40 \%)$, level $(0.38 \%)$, traffic $(0.37 \%)$, aircraft $(0.36 \%)$, fuel $(0.32 \%)$, heading $(0.27 \%)$, airport $(0.27 \%)$, approach $(0.26 \%)$, got $(0.26 \%)$, fire $(0.26 \%)$, number $(0.25 \%)$, speed $(0.25 \%)$, time $(0.24 \%)$, passengers $(0.23 \%)$, minutes $(0.23 \%)$, take $(0.21 \%)$, feet $(0.20 \%)$, smoke $(0.20 \%)$, emergency $(0.20 \%)$, control $(0.20 \%)$, land $(0.19 \%)$, cabin $(0.19 \%)$, turn $(0.19 \%)$, taxiway $(0.19 \%)$, get $(0.18 \%)$, make $(0.18 \%)$, see $(0.18 \%)$, go $(0.18 \%)$, going $(0.17 \%)$, power $(0.17 \%)$, departure $(0.17 \%)$, nose $(0.16 \%)$, report $(0.16 \%)$, descent $(0.15 \%)$, call $(0.15 \%)$, radar $(0.15 \%)$, altitude $(0.14 \%)$, board $(0.14 \%)$, stand $(0.14 \%)$, want $(0.14 \%)$, delay $(0.14 \%)$, lost $(0.14 \%)$, coming $(0.13 \%)$, passenger $(0.13 \%)$.

It is of interest to notice that 100 most frequent notional words cover about $18 \%$ of the entire textual material contained in the 'Exerciser'.

As can be seen, the three most frequent words runway, flight and engine cover more than $2 \%$ of the whole sampling population. 
The average length of a sentence is 7.26 words.

The total number of different words is 2405 .

One essential, in our view, notice. The oftener are specific aviation-relating words or integral word combinations usable in air voice communication, the higher is the probability that the appropriate verbally-denoted objects or actions engage attention of those who handle an aircraft. Thus, the relative frequency priority of some aviation-pertaining lexical means indirectly shows which devices and operations are of primary concern for crewmembers throughout flight.

Among such topical lexical means are 'runway' (its absolute frequency being 272), 'engine' (187), 'flight' (172), 'landing' (125), 'gear' (114), 'traffic' (105), 'aircraft' (102), 'fuel' (91), 'approach' (83), 'heading' (77), 'control' (63), 'taxiway' (60), 'smoke' (57), 'emergency' (56), 'radar' (42), etc.

The terms with a low absolute frequency $(2 ; 1)$ are, in particular, 'hostage', 'propeller', 'stabilizer', 'injuries', 'obstacle', 'run-up', 'transponder', etc., they being very informative due to their sudden appearance in speech communication.

One more notice concerning the 'Exerciser'. Two relaxing procedures are employed in it, they being pictorial visualization (landscapes) and functional music provided to soothe and alleviate tension and contributing to the spontaneous memorization of recurring words and formation of the ability to use automatically and subconsciously the predicative grammatical operations.

The experimental introducing of the 'Exerciser' for the instructing aviation English of first-year flight cadets who were ignorant of the specific aviation terminology and its authentic phrasal usage has proved its evident effectiveness which was manifested in the wholly self-contained, highly motivated and short-term formation of the good command of plain aviation English.

The 'Exerciser' may be regarded as an example of application of phychocybernetic approach to acquirement of aviation English.

The component 'psycho' implies application of external means designed to activate (to 'encourage') psycho-cognitive capacities of learners at the score of using some relaxation means (functional music, landscapes, variative recurrence of words, etc.).

The component 'cybernetic' presupposes provision of through step-by-step controllability of every step made by the learner due to using the separate grammatical operations (e.g. usage of the Simple Tenses / of the Continuous Tenses, etc.) as self sustained units of cognitive activities. It seems significant to add that the subsequent alternate aggregating of the units is obligatory which contributes to the formation of the integral system of the English grammatical Tenses.

The means intended for relaxation render active the main psycho-cognitive modalities of the learners, in the first turn perception, attention and memory. 


\section{Macrothink}

In particular, due to the soothing relaxation means spontaneous memorization of flight-relating words and word collocations as well as unavoidable formation of verbal grammatical automatisms are achieved.

In all known to us instructional and testing materials dealing with the radiotelephony phraseology acquirement its phrasal entries are presented in the integrated, entirely completed solid, continuous form. As a result, the factor of their grammatical componental composition, their specific morphological filling has been overlooked.

In our opinion, the innovational approach in this respect may envisage the morphologically segmented presentation of the phraseology's lingual material for the sake of its training or testing without any applying to native tongue interpretation. We'd like to stress once more that such approach, as far as we are informed, has not been applied up to now.

The approach under consideration can be denoted as movement from a particular to a whole. In other words, it may be considered as the presentation of the radiotelephony entries from inside in contrast with the conventional integrated presentation. It allows every instructor to find out which elements of a concrete phrasal continuity are not steadily fixed in someone's professional memory. The approach applied in this case can be defined as synthesis (formation of ready for use entries of radiotelephony phraseologies) via analysis (their componental presentation).

The morphological components of the phraseology entries dealt with in one more didactic produce developed in the laboratory 'Intramural Checking of Radiotelephony Phraseologies Acquirement' are 'nouns', 'adjectives', 'past participles' in the final and preceding positions, 'prepositions' and 'imperatives'. Certainly, each of the above-mentioned morphological components is treated as a member of a proper, in some cases minimal sufficient, verbal environment - a sentence or a word collocation.

The procedure 'synthesis via analysis' is explicated further with the aid of some proper examples.

\section{Prepositions}






\section{Nouns}

Resume own , magnetic

120 , 40 miles.

$$
\begin{gathered}
\text { distance navigation } \text { track } \\
\text { Is } \_ \text {under } \_ \text {fire }
\end{gathered}
$$

We require medical upon

$$
\text { arrival assistance }
$$

275 for final

runway in

report sight heading

Expedite on final 24.

traffic runway taxi

Past Participles (final position)

Confirm brakes approved

Distress traffic completed

Fuel dumping ended

Frequency change vacated

Maintain FL 350 until further released

Wheels down and locked

Runway advised

Imperatives approach. Report for possible go-around.

Continue a new slot.

Cancel runway vacated.

Prepare RW 28.

Maintain distress.

Request

FL 350 until further advised.

Cross

Adjectives

flock of birds own 


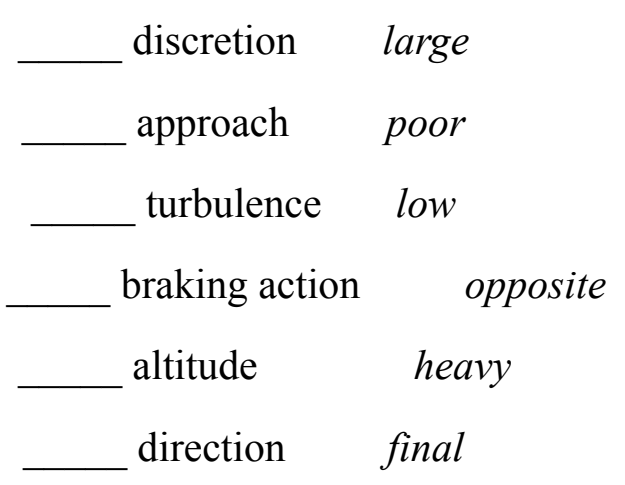

The Laboratory has also developed the electronic didactic means 'Computer-Based Express Checking of Plain Aviation English Competence' provided for the time-pressing testing of the plain aviation English acquisition. This testing means presupposes the time-limited (15 seconds) insertion of the proper finite forms of the verbs to be and to have in the Simple Tenses on condition that the base forms themselves are not positionally designated.

The limit of time is useful as one of the means meant for preparing future pilots and air traffic controllers to act quickly, responsibly but not hurriedly. The task is: 'Insert the proper forms of the verbs to be and to have' ( $p r$ - present, $p$-past, $f$ - future).

(p.) We in bad condition. $\rightarrow$ "We were in bad condition."

$(p r$.$) you sure that you us on the radar at fifty miles? \rightarrow$ "Are you sure that you have us on the radar at fifty miles?"

$(p r$.$) We enough fuel to go around. \rightarrow$ "We have enough fuel to go around."

$(f$.$) What our full weight on takeoff? \rightarrow$ "What will our full weight be on takeoff?"

$(f$.$) We ready to go in about two minutes. \rightarrow$ "We will be ready to go in about two minutes."

(p.) It all your fault. $\rightarrow$ "It was all your fault."

(pr.) We completely on fire. We fire in one of the cargo holds. $\rightarrow$ "We are completely on fire. We have fire in one of the cargo holds."

(p.) We a little better control of the elevator. $\rightarrow$ "We had a little better control of the elevator."

(pr.) How far the airport from here now, please? How far away we from the airport? $\rightarrow$ "How far is the airport from here now, please? How far away are we from the airport?"

$(p r$.$) We a lot of damage to the tail section. \rightarrow$ "We have a lot of damage to the tail section."

The user of the above-mentioned computer-based testing means is required to make a prompt formal structural and contents analysis of the incomplete sentences (the former being one of the procedures used in machine translating) to solve the problem doing the utmost to perform each task on time. Urgency of the correct accomplishment of the task within a very short period of time allows to assess the level of the specialized lingual competency of each user, his grammatical and lexical proficiency.

It seems important to inform that for development of all above-mentioned computer-based 


\section{Macrothink}

instructional and testing means we have employed 'Lazarus IDE' (integrated development environment) which does not require licensing. The means may be handled on laptops, netbooks and desktop PCs with the Windows operating system. We are planning to develop their new versions which will employ the Android OS (operating system). In the latter case, it will be possible to use the offered means on all modern electronic gadgets (smartphones and tablet computers).

The introduction of the instructional and testing means developed on a vast scale will give an opportunity to receive the averaged timed standards for assessment of the rate of execution of every particular concrete task.

Our final remark. It is generally recognized that there is an evident deficit of the instructional materials intended for the basic stage of aviation English instruction. The proposed didactic electronic means are meant to make up to some extent for this lack.

The introducing of the computer-based means under consideration has proved their effectiveness and attractiveness for the users.

\section{Acknowledgement}

We are keenly grateful to Moskalenko H. I., Herasymenko L. S., Alyoshyna H. A., Radul S. H., Bondar A. Y. Izvalov O. V., Zaremba V. V. for their voice-over of our computer-based technologies and priceless assistance in editing the text of the article.

\section{References}

Doc 9835-AN/453. (2010). Manual on the Implementation of the ICAO Language Proficiency Requirements (2nd ed.).

ICAO Manual of Radiotelephony (Doc 9432 AN/925). (2006). Montreal. International Civil Aviation Organization.

Shawcross, Day J. Flightpath. (2011). Aviation English for Pilots and ATCOs. Teacher's book. Cambridge University Press.

Shawcross, Ph. (2011). Flightpath. Aviation English for Pilots and ATCOs. Student's book. Cambridge University Press.

Ellis S., \& Gerighty T. (2008). English for Aviation for Pilots and Air Traffic Controllers. Oxford University Press.

Robertson, F. A. (2009). Airspeak. Pearson Longman. Edinburgh Gate. Harlow. Essex.

Maltz, M. (1960). Psycho-Cybernetics, Simon \& Schuster. New York.

Dan S. Kennedy. (2002). The New Psycho-Cybernetics. Prentice Hall Press. 


\section{Macrothink}

Journal of Social Science Studies

ISSN 2329-9150

\section{Copyright Disclaimer}

Copyright for this article is retained by the author(s), with first publication rights granted to the journal.

This is an open-access article distributed under the terms and conditions of the Creative Commons Attribution license (http://creativecommons.org/licenses/by/3.0/). 